\title{
ECONOMÍA DE GUERRA Y COMERCIO CROSS-CULTURAL EN LA FRONTERA DEL MEDITERRÁNEO ORIENTAL. LA ISLA DE RODAS A MEDIADOS DEL SIGLO XV
}

\author{
Elisa Soldani ${ }^{1}$ \\ Institución Milá i Fontanals, \\ CSIC / Scuola Superiore di Studi Storici di San Marino, RSM
}

\section{RESUMEN}

En la baja Edad Media la isla de Rodas se situaba en una zona fronteriza, un espacio privilegiado para la negociación identitaria donde el comercio crosscultural se mezclaba con la economía de la guerra. A nivel geográfico estaba puesta en un punto de conexión entre importantes rutas comerciales $y$, a la vez, constreñida por los dominios musulmanes, lo que quedaba del Imperio bizantino, las colonias venecianas y genovesas y el Chipre de los Lusignan. Su principal característica era la de ser gobernada por una orden monástico-militar que hacía de la defensa de la Cristiandad su principal razón de ser y que, formalmente, no podía dedicarse directamente a las actividades comerciales. En este artículo se ponen de manifiesto las interacciones entre los Sanjuanistas y los mercaderes de distinto origen y fe que acudían a la isla de Rodas y que apoyaban la Orden en sus necesidades de poblamiento, defensa, abastecimiento y transferencias de dinero.

1 Maria Elisa Soldani. Doctora en Historia Medieval. Institución Milá i Fontanals, CSIC / Scuola Superiore di Studi Storici di San Marino, RSM. C.e: elisasoldani@gmail.com. Este estudio se enmarca en el proyecto de investigación aprobado y financiado por el Ministerio de Educación y Ciencia Español titulado "La Corona de Aragón en el Mediterráneo bajomedieval. Interculturalidad, mediación, integración y transferencias culturales" (HAR2010-16361). Agradezco a Daniel Duran Duelt la revisión y corrección del texto en castellano. 
Palabras clave: Frontera, comercio crosscultural, Rodas, Mediterráneo oriental, mercaderes, Sanjuanistas, cruzada.

\section{ABSTRACT}

In the Middle Ages the island of Rhodes was located in a frontier zone, a privileged space for the negotiation of identities where crosscultural trade mingled with war economy. It was placed at a connection point between major trade routes and, at the same time, constrained by the Muslim dominions, what remained of the Byzantine Empire, the Venetian and Genoese colonies and the Lusignan Cyprus. Its main feature was to be governed by a militarymonastic order that made the defense of Christianity its main purpose and that formally could not directly be engaged in commercial activities. This article will reveal the interactions between the Hospitallers and merchants of different origins and faiths who came to the island of Rhodes, supporting the Order in settlement needs, defense, supplies and money transfers.

Keywords: Frontier, Crosscultural Trade, Rhodes, Easter Mediterranean, Merchants, Hospitallers, Crusade.

En 1440, siendo Jean de Lastic gran Maestre de la Orden de San Juan de Jerusalén, una flota de 18 galeras enviadas por el Sultán de Egipto atacó Rodas. A pesar de la inferioridad numérica, las naves Sanjuanistas consiguieron poner en fuga a la flota mameluca. Sin embargo, ambas partes sufrieron fuertes pérdidas, ya que los mamelucos, de camino a Rodas, habían saqueado la isla de Kastellórizo y devastado Cos. Al contar los eventos en una carta enviada al prior de la Castellanía de Amposta, el Maestre remarcaba que el Sultán, furioso por las pérdidas sufridas, estaba planeando un nuevo ataque a Rodas porque consideraba que, controlando la isla, habría sometido a todos los demás dominios cristianos del Mediterráneo oriental. Esta reflexión del Maestre pone el acento sobre la importancia estratégica de una isla puesta en la frontera entre Cristiandad e Islam. Por otro lado evidencia la preocupación de Lastic que se veía constreñido entre mamelucos y otomanes, sobre todo desde 1438, cuando habían formado una liga. El Maestre no se equivocaba en la valoración de las intenciones del Sultán que, en agosto de 1444, envió nuevamente una flota a atacar Rodas. La fortaleza fue asediada durante cuarenta días al término de los cuales las naves mamelucas, aunque con dificultad, fueron rechazadas de nuevo ${ }^{2}$.

2 Luttrell A., "The Hospitallers at Rhodes 1306-1421", en H. W. Hazard (ed.), A History of the Crusade, vol. V, Madison, 1975, pp. 278-313 y ROssi E., "The Hospitallers at Rhodes 1421-1523", Ibidem, pp. 314-339. 
Fue a aquel tipo de situaciones a las que debió hacer frente Jean de Lastic durante los años de su gobierno (1437-1454), un contexto en el que se hacía necesario el hallazgo urgente de recursos humanos y económicos, lo que dio lugar a una reorganización de las finanzas y a una reflexión sobre la gestión de las posesiones orientales. Los gastos que tuvo que afrontar eran, por ejemplo, los relativos a las fortificaciones y a la reconstrucción de los lugares saqueados, los salarios de guardias y asalariados, el equipamiento de las naves y los aprovisionamientos, la financiación del passagium de los caballeros convocados a Rodas desde los dominios occidentales, junto con los gastos de las embajadas enviadas incesantemente hacia la Europa latina o a las potencias colindantes.

La financiación de las iniciativas militares permanentes que la Orden llevaba a cabo en el Mediterráneo oriental se basaba en un sistema tradicional de recaudación, con la implementación de medidas extraordinarias cuando se debía hacer frente a operaciones y, en consecuencia, a pagos puntuales. El Convento o cuartel general sanjuanista tenía su sede central en Rodas de la cual dependía una red de prioratos y comandas en Occidente, una organización internacional con intereses en toda la Europa latina, importantes tanto como recurso financiero como para el reclutamiento de los hombres. Eran las receptorías el corazón organizativo de esta red de posesiones: en semejantes departamentos económicos territoriales los depositarios locales se encargaban, mediante la concesión de poderes emitidos por el tesorero general, de recaudar las responsiones y los demás derechos debidos al Tesoro y de transmitirlos a Rodas ${ }^{3}$.

Después del asedio de 1444 el Tesoro había contraído una deuda de alrededor de 150.000 ducados de Rodas. En este momento de dificultad el

3 Los prioratos eran los de Tolosa, Saint Giles, Auvernia, Francia, Champagne, Aquitania, Navarra, Castilla y León, Portugal, Lombardía, Venecia, Pisa, Roma, Barletta, Capua, Messina, Inglaterra, Irlanda, Alemania, Bohemia, Hungría, Dacia, Cataluña e la Castellanía de Amposta. Para el periodo aquí analizado el sistema de recaudación de la Orden en Occidente ha estado estudiado a nivel general por SARNOWSKY J., Macht und Herrschaft, pp. 469-582 y ID., "The Rights of the Treasury': the Financial Administration of the Hospitallers on Fifteenth-Century Rhodes, 1421-1522", en Nicholson H. (eds.), The Military Orders. Vol. II. Welfare and Warfare, Aldershot, 1998, pp. 267274 y a nivel local por BONNEAUD P., Le prieuré de Catalogne, le couvent de Rhodes et la couronne d'Aragon 1415-1447, Millau, 2004, pp. 81-86. Sobre la transferencia de recursos económicos desde los dominios occidentales véase también VANN T. M., "The Exchange of Information and Money between the Hospitallers of Rhodes and their European Priories in the Fourteenth and Fifteenth Centuries", en Burgtorf J. y Nicholson H. (eds.), International Mobility in the Military Orders (Twelfth to Fifteenth Centuries): Travelling on Christ's Business, Cardiff, 2006, pp. 35-47. 
Maestre autorizó varias medidas para cubrir el hueco financiero ${ }^{4}$. La intensificación de la presión en esta zona de frontera puso en evidencia la necesidad de reorganizar el sistema para que fuera más eficiente y de recorrer a los servicios de banqueros internacionales, en particular de aquellos bancos florentinos romanam curiam sequentes que ya ofrecían sus propios servicios a la curia tanto en el marco de la administración de las finanzas papales como en la recaudación de las decimas para la cruzada. No era tan sólo la actividad bancaria la que interesaba a estos operadores, sino que aquélla se perfilaba también como una oportunidad excelente para insertarse en un área dominada por otros grupos. ${ }^{5}$

La necesidad de liquidez y de servicios en la isla favoreció por lo tanto la consolidación de algunas prácticas mercantiles y crediticias en colaboración con mercaderes y banqueros que, como los Sanjuanistas, tenían intereses no tan sólo en la isla, si no más ampliamente en el Mediterráneo oriental -Constantinopla, Pera, Creta, Quíos, Chipre y Egipto- y en las principales plazas comerciales y financieras europeas. Por otro lado, la misma posición de Rodas - constreñida como estaba por los dominios musulmanes, lo que quedaba del Imperio bizantino, las colonias venecianas y genovesas y el Chipre de los Lusignan- colocaba a la Orden en la tesitura de tener que negociar con instituciones heterogéneas. Para gestionar esa compleja situación los hospitalarios necesitaron recurrir a profesionales relacionados con los servicios de transporte, suministro de mercancías y avituallamiento, así como de los servicios bancarios de transferencia, cambio y adelanto de dinero, con numerosas competencias lingüísticas, culturales y diplomáticas necesarias tanto para llevar a cabo operaciones mercantiles, como para contraer acuerdos comerciales, treguas, paces y para negociar el rescate de cautivos. ${ }^{6}$

4 BONNEAUD P., Els hospitalers catalans..., pp. 253-255.

5 Sobre los servicios financieros prestados a la Orden por los banqueros florentinos véase SOldani M. E., Duran i DuElt D., "Religion, Warfare and Business in Fifteenth Century Rhodes, en Religion and religious Institution in the European Economy. 1000-1800", Acts of the XLIII Study Week, AmmanNATI F. (ed.), Fondazione Istituto Internazionale di Storia Economica "F. Datini", Florencia, 2012, en part. el parráfo 3. Between Rhodes and ultramarine domains: the relationship of Hospitallers and Florentine merchant-bankers.

6 Sobre la diplomacia en esta área Schabel C., Beihammer A. y Parani M. (eds.), Diplomatics in the Eastern Mediterranean 1000-1500. Aspects of Cross-Cultural Communication, Leiden, 2008. Para una comparación con el uso de la diplomacia en la frontera del Mediterráneo occidental SALiCRú i LluCH R., "La diplomacia y las embajadas como expresión de los contactos interculturales entre cristianos y musulmanes en el Mediterráneo occidental durante la baja Edad Media", Estudios de Historia de España, 9 (2007), pp. 77-106. 
A raíz de estas reflexiones, el objetivo de este ensayo es el de comprender cómo, en esta especifica área de frontera del Mediterráneo oriental, se integró la economía de la guerra con el comercio cross-cultural, analizando de qué forma los caballeros intentaron atraer y, por lo tanto, beneficiarse de la presencia en la isla de operadores multiculturales allá establecidos o de pasaje: en momentos de especial necesidad ¿cómo y por cuáles razones la Orden se sirvió de la colaboración de mercaderes latinos, griegos, judíos y musulmanes?, ¿qué encargos se les confió?, ¿de qué modo la Orden, tanto en épocas de paz como de guerra, garantizó sus derechos de propiedad y el respeto de los contratos?

\section{LOS SANJUANISTAS Y LA DEFENSA DE LA CRISTIANDAD: LA AM- BIGÜEDAD DE LA FRONTERA}

Desde el momento en que los Caballeros de San Juan de Jerusalén se desplazaron de Tierra Santa a Rodas, a principio del siglo XIV, la isla se convirtió en un bastión de la defensa de la Cristiandad que fue incrementando su propio valor estratégico ante de los ataques mamelucos de 1440 y 1444 y la conquista otomana de Constantinopla de $1453^{7}$. Si originariamente la primera función de la Orden había sido la de proporcionar defensa y hospitalidad a los peregrinos y de ofrecer curas a los enfermos, ésa fue disminuyendo junto con el número de peregrinos, que cada vez se dirigían en menor número hacia los lugares sacros ya puestos bajo el dominio de quien las fuentes de la época definían como el Sultán de Babilonia. En el siglo XIV, en efecto, exceptuando la participación en algunos proyectos de cruzada o en ligas locales, los Sanjuanistas no habían adoptado una política ofensiva activa, sino más bien una actitud prudente, dirigida a la defensa y a la consolidación de sus propias posiciones en esta área del Mediterráneo oriental. Fue prevalentemente en el siglo siguiente y en concomitancia con los cambios geopolíticos del Mediterráneo oriental que la actividad de los Sanjuanistas se fue concentrando cada

7 Sobre la Orden en Tierra Santa, en Chipre y en Rodas: Riley-SMith J., The knights of St John in Jerusalem and Cyprus c. 1050-1310, Londres, 1967; LuTTRELl A., The Hospitallers in Cyprus, Rhodes, Greece and the West, 1291-1440 collected studies, Londres, 1978; ID., Latin Greece, the Hospitallers and the Cursades, 1291-1440, Londres 1982; ID., The Hospitallers of Rhodes and their Mediterranean World, Londres, 1992; ID., The Hospitaller State on Rhodes and its Western Provinces, 1306-1462, Londres, 1999; ID., Studies on the Hospitallers after 1306: Rhodes and the West, Londres, 2007; BORCHARDT K., JASPERT N. y NiCHOLSON H. J. (eds.), The Hospitallers, the Mediterranean and Europe: Festschrift for Anthony Luttrell, Aldershot, 2007; VaTin N., Rhodes et l'ordre de Saint-Jean-de-Jérusalem, Parigi, 2000; SARNOWSKY J., Macht und Herrschaft im Johanniterorden des 15. Jahrhunderts. Verfassung und Verwaltung der Johanniter auf Rhodos (1421-1522), Münster, 2001. 
vez más en aquellas operaciones ofensivas con carácter constante típicas de la frontera -como el corso- o bien en verdaderas expediciones coherentes con el papel que la Cristiandad latina y el papado atribuían a la Orden y que justificaba sus posesiones orientales y europeas. Los caballeros debían llevar a cabo una lucha permanente contra "el infiel" que, junto con el rescate de los cautivos cristianos, constituía su propia razón de ser, sobre todo tras la supresión de los templarios (1312).

Esta función que los Sanjuanistas desarrollaban en Oriente comportaba el mantenimiento de una flota, la organización de estructuras de defensa terrestre, la acumulación de vituallas en caso de asedio y la recaudación constante de recursos monetarios. Tenían, además, la necesidad de gestionar una intensa actividad diplomática dirigida a obtener ayudas militares y financieras, movilizando las conciencias de los príncipes cristianos con una llamada continua a la cruzada anti-turca. Era a través de la acción diplomática, con la que la Orden sostenía sus propias operaciones bélicas, que se construía una imagen unitaria de ese frente latino nada compacto. El Mediterráneo oriental estaba más bien dividido en áreas de influencia entre los venecianos y genoveses con sus tradicionales enclaves dependientes de la metrópoli occidental y en el que otra potencia había adquirido cada vez más relevancia, no tan solo desde la perspectiva de sus mercaderes, la Corona de Aragón, gracias a la conquista de Sicilia, Cerdeña y, finalmente, del reino de Nápoles ${ }^{8}$. Al lado de Rodas estaba también el Chipre gobernado por los Lusignan, donde los hospitalarios poseían una de sus comandas más importantes. En este contexto en el que la prioridad de venecianos, genoveses y catalanoaragoneses, pero también anconitanos y provenzales, era defender a sus propios intereses comerciales, además de proteger sus propias posesiones, las potencias latinas no fueron siempre aliadas de la Orden, verificándose, más bien, constantes acciones de piratería entre unos y otros. Fueron años en los que equilibrios y afinidades en el Mediterráneo oriental fueron también el reflejo de las guerras itálicas entre estados territoriales.

En esta área el papel de defensa de la Cristiandad por parte de venecianos y genoveses fue mucho más ambiguo con respecto, por ejemplo, al que asumieron las monarquías más expuestas a la frontera, las cuales, en cambio, reclamaban una posición central en lo que se ha definido la "geografía mental

8 MARINESCU C., La politique orientale d'Alphonse V d'Aragon, roi de Naples (1416-1458), Barcelona, 1994; DURAN I DUElT D., Kastellórizo, una isla griega bajo dominio de Alfonso el Magnánimo (1450-1458). Colección documental, Barcelona, 2003, pp. 16-17, 26-27. 
de la Cristiandad"9. Aquí las potencias mercantiles se jugaban importantes intereses comerciales. Cada uno de estos actores a nivel institucional, a través de acuerdos bilaterales, treguas o por iniciativa de los mismos mercaderes, podía subvencionar o favorecer al "infiel" con suministros de armas o barcos. Se podía dar también la situación inversa, ya que la Orden misma se sirvió de súbditos del sultán mameluco y del otomano tanto en el abastecimiento de la isla como en operaciones concretas como el rescate de cautivos. Para asegurarse la presencia en la isla de estos operadores multiculturales, la Orden debía garantizarles el respecto de sus personas y de sus bienes, tanto en épocas de paz como de guerra. Se trataba de personajes que debían de despertar un sentido de proximidad cultural y de "familiaridad" en el interlocutor, gozando también de la confianza por parte de los sanjuanistas, ya que, al confiarles encargos delicados, siempre existía el riesgo de que actuaran como espías o favorecieran al enemigo. En marzo de 1448 el Maestre volvía a remarcar que durante el tiempo en que la paz restablecida en 1445 había tenido validez, Rodas había estado abierta a los súbditos del Soldán de Egipto y sin gravámenes de otros impuestos que no hubieran sido los pagados por los latinos ${ }^{10}$. Aún en 1450 se refrendó un acuerdo comercial entre los Sanjuanistas y el Gran Turco por el cual se otorgaba también a los mercaderes otomanos el acceso al puerto de Rodas ${ }^{11}$. Esto ocurría en tiempos de paz, pero en épocas de guerra también se otorgaron salvoconductos nominales que permitían a determinados mercaderes y patrones procedentes de Alejandría o de la Península Anatólica hacer escala en Rodas con sus propias naves, a pesar de que transportaran moros o bienes pertenecientes a moros.

\section{EN EL CORAZÓN DEL MEDITERRÁNEO ORIENTAL: LA POSICIÓN ESTRATÉGICA DE RODAS}

Rodas, la más oriental de las islas del Egeo, ocupaba una posición clave en el Mediterráneo oriental, situada en el punto de conexión entre áreas políticas y ecológicas distintas, justo en la intersección de las rutas que llevaban a Constantinopla y al Mar Negro, por un lado, y a Chipre, Beirut y Alejandría, por el otro. La isla, con sus aproximados $1.400 \mathrm{~km}^{2}$ de superficie, se encontraba y se

9 Sobre la elaboración del concepto de Christianitas Berend N., "Défense de la Chrétienté et naissance d'une identité. Hongrie, Pologne et péninsule Ibérique au Moyen Âge", Annales HS, 58/5 (2003), pp. 1009-1027.

10 Archivos de la Orden de Malta (AOM) 360, c. 212r (6 de marzo 1448), doc. pubbl.

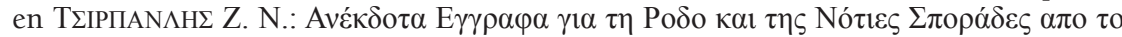

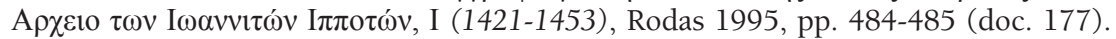

11 BONNEAUd P., Els hospitalers..., p. 258. 
encuentra a poco menos de $18 \mathrm{~km}$. de la costa turca, donde la Orden poseía la avanzada del Castillo de San Pedro, situado en los alrededores de la antigua ciudad de Halicarnaso, la actual Bodrum. La ciudad de Rodas impresionaba a los peregrinos y viajeros por sus fortificaciones, necesarias por esa extrema cercanía con Turquía, de la cual la separaba "un pequeño brazo de mar"12.

Los Sanjuanistas habían establecido la propia soberanía no tan sólo sobre Rodas, sino también sobre el resto del archipiélago del Dodecaneso ${ }^{13}$. En esta área de dominación latina constreñida por los estados mameluco y otomano, el comercio internacional se unía indisolublemente con la economía de la cruzada, es decir, con la economía que giraba alrededor de aquellas operaciones bélicas de frontera que ya no estaban dirigidas a la reconquista de los territorios, si no, más bien, a la contención de la avanzada enemiga. A partir de esas islas los hospitalarios, con su propia flota o otorgando licencias de corso, saqueaban las naves mamelucas y hacían, además de botines, prisioneros que en un segundo momento podían servir para el intercambio con los cautivos cristianos. El Convento y el Maestre, aunque no se opusieran a las iniciativas de los hermanos que, con sus propios medios o asociándose a mercaderes, pagaban y armaban buques corsarios, entendió la necesidad de mantener este asunto bajo control: desde 1413 estas operaciones se consideraron legítimas si estaban dirigidas hacia los "infieles" y autorizadas con una licencia".

El tipo de dominio sanjuanista sobre Rodas y el peculiar posicionamiento geopolítico de la isla concurrieron en el desarrollo de una sociedad multicultural, caracterizada por una enorme fluidez social e identitaria. En la isla, una Orden multinacional de origen latino gobernaba una población compuesta por latinos, griegos ortodoxos, judíos y musulmanes ${ }^{15}$. Rodas es-

12 Nompar de Caumont, "Le Voyage d'outre-mer à Jérusalem", B. DANSETTE (ed.), en D. RÉGNIER-BOHLER (dir.), Croisades et pèlerinages. Récits, chroniques et voyages en Terre Sainte XIIe-XVIe siècle, Paris, 1997, pp.1057-1167. En cuanto a las impresiones de los viajeros véase también BALARD M., "The Urban Landscape of Rhodes as perceived by Fourteenth- and Fifteenth-Century Travelers", en Arbel B. (ed.), Intercultural Contacts in the Medieval Mediterranean, Londres, 1996, pp. 24-35.

13 La Orden gobernaba, además de Rodas, las islas de Alimnia, Chalki (Halki), Simi, Tilos, Nisiro, Cos (Lango), Calino (Kalimnos), Lero (Leros) y, hasta 1450, Kastellórizo. Sobre el paso de Kastellórizo a soberanía de Alfonso el Magnánimo DURAN i DUELT D., Kastellórizo, una isla griega bajo dominio de Alfonso el Magnánimo (1450-1458). Colección documental, Barcelona, 2003.

14 Bonneaud P., Els hospitalers catalans a la fi de l'edat mitjana: l'orde de l'Hospital a Catalunya i a la Mediterrània, 1396-1472, Lleida, 2008, p. 249.

15 SARNOWSKY J., Macht und Herrschaft im Johanniterorden des 15. Jahrhunderts. Verfassung und Verwaltung der Johanniter auf Rhodos (1421-1522), Münster, 2001, pp. 345-375. Cabe destacar que entre los judíos había varios médicos y cirujanos que trabajaban en la Enfermería. 
taba, en efecto, puesta en una zona de contacto entre poblaciones de distinto origen, cultura y credo. Los salvoconductos demuestran cómo mercaderes musulmanes y judíos llegaban también del Mediterráneo occidental para actuar como intermediarios boundary-crossing: dos ejemplos de ello son el musulmán valenciano Galip Ripoll, sobre el cual se volverá más adelante, y David Sulla, judío de Marsella, al que, en 1438 se otorgó un salvoconducto de tres meses ${ }^{16}$.

Hubo, pues, relaciones dinámicas de intercambio cross-cultural entre actores de distintos orígenes geográficos, culturales y religiosos ${ }^{17}$. En esta zona de frontera las relaciones con las potencias musulmanas no fueron exclusivamente hostiles, ni siquiera para esta orden monástico-militar que hacía de la defensa de la Cristiandad su principal razón de ser. De hecho, simultáneamente a las actividades bélicas tenían lugar transacciones comerciales que se realizaban gracias al servicio de estos particulares agentes mediadores ${ }^{18}$.

\section{LA GESTIÓN ECONÓMICA DE UNO DE LOS EMPORIA MÁS IMPOR- TANTES DEL LEVANTE}

Desde la perspectiva económica, la fuerte peculiaridad de Rodas como isla fundamental comercialmente hablando era el hecho de estar gobernada por una orden monástico-militar. El emporium formaba parte de un imperio terrestre organizado a partes inversas con respecto a los dominios venecianos y genoveses en el área, en el sentido que eran las posesiones que

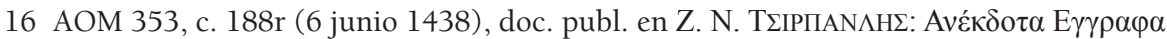
$\gamma 1 \alpha \ldots$, p. 326 (doc. 75). Sobre el papel de los mudéjares en la embajadas intercambiadas por la Corona de Aragón con el Sultán de Granada o los poderes del Magreb SAlicrú i LlUCH R., "La diplomacia y las embajadas como expresión de los contactos"..., pp. 84-85; ID., "Crossing Boundaries in Late Medieval Mediterranean Iberia: Historical Glimpses of Christian-Islamic Intercultural Dialogue», International Journal of Euro-Mediterranean Studies, 1/1 (2008), pp. 33-51.

17 Sobre el uso del término 'intercultural' TRIVELlato F, "Juifs de Livourne, Italiens de Lisbonne, hindous de Goa. Reseaux marchands et échanges interculturels à l'époque moderne", Annales HSS, 58/3 (2003), pp. 581-603. La expresión cross-cultural trade designa relaciones de crédito y de negocios prolongadas entre mercaderes que no comparten lazos de sangre, parentesco o etnia; CURTIN P., Cross-Cultural Trade in World History, Cambridge, 1984. Para una problematización del concepto de sociedad de frontera y para las referencias bibliográficas esenciales BEREND N., «Preface», en ABUlafia D. y Berend N. (eds.), Medieval frontieres: concepts and practices, Aldershot, 2002, pp. 133-142 y, en el mismo volumen, BALARD M., "Genuensis civitas in extremo Europae: Caffa from the Fourteenth to the Fifteenth Century", Ibidem, pp. 143-151.

18 Para una comparación con la experiencia de los Caballeros Teutónicos en el Norte de Europa MAŽEIKA R., "Of cabbages and knights: trade and trade treaties with the infidel on the northern frontier, 1200-1390", Journal of Medieval History 20/1 (1994), pp. 63-76. 
los Sanjuanistas tenían en la Europa latina las que dependían de Rodas y no al revés. Además, desde el punto de vista normativo a los miembros de la Orden se les vetaba cualquier tipo de transacción comercial que comportara una verdadera ganancia sobre la mercadería así como cualquier involucración en actividades usurarias como préstamos a interés. Una norma perteneciente a los estatutos de la época del maestre Antoni Fluvià, antecesor de Lastic, lo declaraba claramente: «Quod fratres non exerceant mercimonia. Indecorum et grave quidem censeri debet, qui religionis professioni ac fidei catholice tuitioni, cui tota mente obsequi debent, dicati sunt, mercimoniorum negotiationi se sollicita cura ascribere. Prohibemus igitur, ne fratres ordinis nostri, cuiscunque conditionis fuerint, mercimonia exercere presumant, hoc est emere et vendere res mercantiles lucri gratia». La crisis financiera de los años cuarenta y cincuenta del siglo XV llevó, sin embargo, a la Orden a hacer excepciones relevantes en este punto, aunque más tarde, en 1476, se habría vuelto a repetir quod negociacio est prohibita per nostra stabilimenta ${ }^{19}$.

Por lo tanto, en esta isla económicamente tan importante los Hospitalarios, como institución que la gobernaba, no habrían tenido que verse directamente involucrados en el provecho comercial. Teóricamente no habrían podido realizar transacciones comerciales para ellos mismos, sino, más bien, limitarse a cobrar beneficios fiscales relativos a la recaudación de los derechos aduaneros, a los impuestos del puerto y a la concesión en arrendamiento de los recursos económicos de la isla. Los derechos ordinarios que se pagaban sobre la entrada y salida de mercaderías -las distintas entradas del commerchium o, por ejemplo, la gabela de la harina y del vino- podían ser dados en arriendo para garantizarse anticipos de dinero y/o aumentar cuando se incrementaban los gastos ordinarios de defensa de la ciudad de Rodas. Esto ocurrió en 1437, cuando Lastic convocó a los cabezas de familia rodiotas para renovar el impuesto del $8 \%$ sobre todas las mercancías, subiéndolo un medio punto porcentual destinado, entre otras cosas, a pagar las defensas de la ciudad. La Orden, pues, sacaba beneficios de la explotación de los recursos del archipiélago: tanto de la producción de azúcar en la gran preceptoría chipriota de Colossi, como de los arrendamientos de la ceca y de las jabonerías, entre otros. Estas entradas podían ser asignadas a los acreedores, en caso que, al tener que devolver las cantidades prestadas, las cajas del Tesoro se encontraran vacías.

19 Stabilimenta Rhodiorum militum: due Statuten de Johanniterordens von 1489/93, HAECKER J. y SARNOWSKY J. (eds.), Göttingen, 2007, pp. 220. Sobre las cuestiones relativas a la gestión de las finanzas SARNOWSKY J., Macht und Herrschaft..., pp. 512-524. 
En Rodas los Sanjuanistas ponían a disposición de los mercaderes un emporium abierto al mar, provisto de órganos de mediación, infraestructuras portuarias, almacenes, alojamientos para marineros y edificios administrativos. Aquellos que pasaban por Rodas quedaban impresionados por las torres, la muralla, el palacio del Maestre, los molinos de viento y los exuberantes jardines. La ciudad respondía a una división jerárquica de los espacios, en la que estaba claramente marcada la separación entre el castillo habitado por los Hospitalarios y el burgo donde residía el resto de la población. Los caballeros vivían en el collachium puesto en el centro del espacio urbano, allá donde estaba situado el antiguo castrum bizantino, en la cumbre del cual surgía el palacio del Maestre; abajo, en el burgus, residían en cambio todos los sujetos a los Sanjuanistas, y entre ellos mercaderes, marineros y artesanos. El puerto comercial se abría al Este y al Sur de aquél se encontraban el barrio judío y la sinagoga ${ }^{20}$.

En la sociedad multicultural de la ciudad, destacaban, en el campo comercial, los mercaderes latinos, los cuales operaban allí en parte colectivamente, en la medida en que las distintas naciones dependían de instituciones diversas que podían intervenir -siendo también un reflejo de los equilibrios de poderes entre los distintos componentes de la Orden- para defender la prerrogativas de miembros del propio grupo, y en parte individualmente, porque se establecían relaciones directas entre el Maestre y el Tesoro con los mercaderes a nivel individual, no tan sólo con aquellos considerados rodiotas, sino también con los que estaban de paso y no se habían asentado establemente en la isla. Los mercaderes itinerantes llevaban a cabo sus negocios allí a través de salvoconductos o letras patentes otorgados por el Maestre o el Convento para un periodo determinado de tiempo, mientras que otros, más estables, habían conseguido la ciudadanía con todas las consecuencias fiscales que eso comportaba, habían contraído matrimonio y, en algún caso, hasta habían logrado entrar en la Orden.

En la tutela de las actividades mercantiles que se desarrollaban en este emporium la organización militar y la diplomacia tenían un papel fundamental: la seguridad de la isla estaba salvaguardada por la confianza puesta en las fortificaciones, en la fuerza naval y en el consenso de las potencias que comerciaban en el mar mediante acuerdos contraídos entre imperios terrestres, paces y treguas conseguidas a través de una intensa actividad diplomática.

20 Balard M., Les Latins en Orient XIe-XVe siècle, Paris, 2006, pp. 315-319. 


\section{LAS POLÍTICAS DE POBLAMIENTO Y ABASTECIMIENTO DE RODAS}

Fernand Braudel en su obra clásica La Méditerranée et le Monde Méditerranéen a l'époque de Philippe II dedicó un párrafo a la precariedad de las islas. En aquellas líneas llamó la atención sobre el hecho que las islas, al no ser casi nunca autosuficientes, siempre estuvieron amenazadas por las carestías y la belicosidad del mar ${ }^{21}$. Rodas tuvo el mismo problema, sobre todo ante el incremento de la belicosidad marítima. Por esta razón los Sanjuanistas recurrieron a medidas dirigidas a la repoblación de la isla y, tras la oferta de salvoconductos y condiciones comerciales especiales, a atraer a los mercaderes que habrían podido contribuir a los servicios de avituallamiento y de defensa marítima ${ }^{22}$. En 1438 eran dos genoveses, Raffaele Vivaldi y Niccolò Italiano los que consiguieron la concesión del derecho de residencia en la ciudad y en la isla pudiendo ejercer como mercaderes, mientras que a Petro Cassella le fue permitido ir a habitar a Rodas con su mujer ${ }^{23}$. El año siguiente Lastic mencionaba y confirmaba una concesión de cinco años otorgada por su predecesor al cremonés Antonio Villadana y a sus socios de incohando artem fustanorum en la ciudad de Rodas, en la que se establecía que sólo los que hacían parte de esta sociedad pudieran llevar y vender fustanes en la isla ${ }^{24}$.

Aquellos salvoconductos, a los que acompañaban simultáneamente beneficios fiscales y comerciales, probablemente tuvieron como finalidad atraer gente a Rodas con el propósito tanto de poblar la isla y volverla más segura como de proveerla de ciertas tipologías de bienes y de sujetos que pudiesen desarrollar servicios útiles en ese clima de crisis diplomáticas, ataques y asedios, como mercaderes, marineros y artesanos. Otra forma de hacer confluir recursos humanos y financieros en Rodas fue la concesión de salvoconductos especiales que permitían el regreso de los mercaderes bandeados, aquéllos que muy a menudo habían dejado la isla para huir de los acreedores. Se trataba de medidas que coincidían, además, con la política de Fluvià, antes, y

21 BRAudel F., Civiltà e imperi del Mediterraneo nell'età di Filippo II, 2 voll., Turín, 2002, vol. I, pp. 146-158.

22 ID., "Servitudo Marina at Rhodes: 1306-1462", in The Hospitallers in Cyprus, Rhodes, Greece and the West, 1291-1440: collected Studies, IV, Londres, 1978, pp. 50-51.

23 AOM 353, c. 15lv (1 abril 1438) e AOM 353, c. 188r (13 junio 1438), doc. publ. en

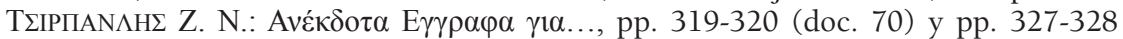
(doc. 77).

24 AOM 353, c. 151v (1 abril 1438); AOM 353, c. 188r (13 junio 1438); AOM 354, c.

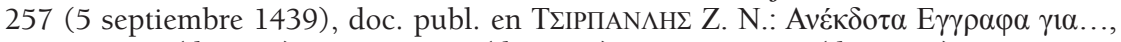
pp. 319-320 (doc. 70), pp. 327-328 (doc. 77 ) y pp. 364-366 (doc. 102). 
de Lastic, después, de convocar a los hermanos a Rodas desde los prioratos occidentales ${ }^{25}$.

Para subvenir a las necesidades urgentes de liquidez en la isla el Tesoro recurrió a préstamos contraídos con los mercaderes latinos y, forzados, con los judíos de la isla. El gobierno de Jean de Lastic, de hecho, se abrió con una de estas operaciones. El 26 de noviembre de 1437 el Tesoro tomó forzosamente en préstamo de Ezechiel Mauristiri, judío, 1.152 florines de Rodas, cantidad que el nuevo maestre, que se encontraba todavía in partibus Occidentis, debía al Convento con ocasión de su elección. El judío había pagado la cantidad equivalente en ducados de Rodas, 720 ducados, que Lastic se comprometía a devolverle en Rodas con interés, si occurreret. Al judío se asignaban los ingresos de la jabonería y otros derechos del commerchium que correspondían al Maestre. El mismo tipo de préstamo fue contratado por el Tesoro con Suffredo Calvi, que bajo la misma modalidad prestó la cantidad equivalente a 2.000 florines de oro de Rodas en ducados siempre de Rodas, garantizados por los bienes de la Orden y sobre los derechos fiscales del Maestre ${ }^{26}$.

A veces a los mercaderes les fue requerido pagar directamente los gastos militares. Las cantidades anticipadas en Rodas se habrían pagado a través de las preceptorías occidentales. El primer día de marzo de 1450 el tesorero acordó con los genoveses Bartolomeo Doria y Nicolò Italiano que se comprometieran, por lo menos durante un año, a pagar cada dos meses el sueldo de las gentes de armas del Castillo de San Pedro. En caso de que no hubiesen satisfecho a tiempo los pagos, el Tesoro se reservaba la posibilidad de tomar en préstamo el dinero necesario de otros mercaderes haciendo recaer el interés sobre los genoveses. En cuanto a la restitución de las cantidades, se establecía que fuesen pagadas por el conservador del Tesoro en Aviñón a dos meses vista a partir de la fecha del pago del último sueldo previsto, en letras de cambio dirigidas, como beneficiarios, a los factores del Doria y del Italiano.

Otros servicios que podían fácilmente ser comisionados a los mercaderes eran los relacionados con la compra y el flete de barcos o el abastecimiento de cereal y, más en general, el avituallamiento de la isla. Nicolau Correguer en 1449 vendió una nave de su propiedad a la Orden por 2.950 ducados de $\operatorname{Rodas}^{27}$. Las galeras de las que eran propietarios los mercaderes fueron

25 BONNEAUD P., Els hospitalers catalans...

26 AOM 353, 150v-151r (16 noviembre 1437) y AOM 353, 150r-v (29 noviembre 1437),

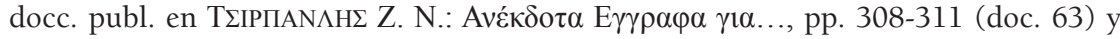
pp. 311-314 (doc. 64).

27 AOM 361, c. 291r (9 octubre 1449). 
también empleadas en operaciones bélicas. En principio la Orden podía reunir recursos suficientes para mantener una flota que se ocupara de la defensa de Rodas y de las demás islas del archipiélago, pero en momentos de elevada conflictividad tenía que procurarse barcos fletándolos a mercaderes, mayoritariamente genoveses pero también, a mediados del XV, catalanes ${ }^{28}$. Un ejemplo elocuente de esa práctica es el hecho que de las ocho galeras que habían participado en las operaciones para levantar el asedio de 1444, cuatro habían sido fletadas a dos mercaderes catalanes que practicaban habitualmente el comercio con Rodas -Jofre Sirvent y Ferrer Bertran- y a dos piratas -el valenciano Jaume de Vilaragut y el catalán Gracià de Monsoriu ${ }^{29}$. También las operaciones de abastecimiento relacionadas con envíos de trigo desde Sicilia e Italia del Sur involucraron a menudo a patrones catalanes y mallorquines ${ }^{30}$. Al mismo tiempo la población griega rodiota estaba en principio sujeta a un sistema de prestación forzada de servicios personales llamada servitudo marina, por el cual los hombres mayores de diecisiete años, inscritos en un registro del que era responsable el almirante, estaban obligados a prestar una corvea como marineros en las galeras sanjuanistas cuando se hacía necesario ${ }^{31}$.

También los rodiotas proveían al Convento de vituallas en el área levantina, recurriendo por ejemplo a los despotados griegos: éste fue el caso de Francesco Belli enviado con su griparia a Arta, capital del despotado de Epiro, a proveerse de trigo y cebada ${ }^{32}$. Una serie de salvoconductos y letras patentes otorgadas entre los años treinta y cincuenta atestiguan un vaivén entre Rodas y la península Anatólica de mercaderes griegos y turcos al servicio

28 Rossi E., Storia della marina dell'Ordine di San Giovanni di Gerusalemme, di Rodi e di Malta, Roma-Milano, 1926, pp. 7-22; LutTrell A., "Emmanuele Piloti and the Criticismo of the Knights Hospitallers of Rhodes: 1306-1444", Annales de l'Ordre Souverain Militaire de Malte 19 (1962), pp. 11-17.

29 BONNEAUD P., Els hospitalers catalans..., pp. 251-252.

30 SaRnowsky J., Macht und Herrschaft, pp. 394-397; Trasselli C., Sicilia, Levante e Tunisia nei secoli XIV e XV, Trapani 1959, pp. 13-29; ALIBRANDI M., "Messinesi in Levante nel Medioevo", Archivio Storico Siciliano, ser. III, XXI-XXII (1971-1972), pp. 97-110; MARINESCU C., La politique orientale, pp. 47-48; DURAN I DUELT D., "De l'autonomia a la integració: la participació siciliana en el comerç oriental als segles XIV i XV", en M. T. FERRER I MALlOL, MUTGÉ I VIVES J. (eds.), La Corona catalanoaragonesa i el seu entorn mediterrani a la Baixa Edat Mitjana, Barcelona, 2005, p. 84; ID., "Els mallorquins a la Romania (segles XIII-XVI)", en BARCELÓ CRESPí M., El Regne de Mallorca: cruilla de gents i de cultures (segles XIII-XV), Palma de Mallorca, 2008, pp. 241-255.

31 Luttrell A., "Servitudo Marina at Rhodes: 1306-1462", in The Hospitallers in Cyprus, Rhodes, Greece and the West, 1291-1440: collected Studies, IV, Londres, 1978, pp. 50-65.

32 AOM 363, c. 242v (23 septiembre 1451). 
de la Orden que se ocupaban de abastecer la isla. En 1438 un salvoconducto fue concedido a Abrahaam Bay, griego nacido en Antalya, y a sus familiares y factores, puesto que Abraham navegaba y negociaba mercancías pertenecientes a la Orden ${ }^{33}$. Otros dos griegos habitantes 'en las partes de Turquía', Papa Georgi y Basili tu Schuastu, viajaban por mar junto con dos turcos, Mustaffá y Haly, llevando avituallamientos a Rodas ${ }^{34}$. Un mercader que, el mismo año, "iba y venía" de Rodas hacia Siria y Egipto llevando consigo dinero y mercancías de rodiotas era un sirio de nacimiento - con toda probabilidad un cristiano- llamado Marco Salvatore ${ }^{35}$. Aún en 1452 el que viajaba entre las terrae infidelium y Rodas era el turco Habraym costumato venire di Turchia a Rhodo e da Rhodo in Turchia ${ }^{36}$.

\section{NEGOCIOS CON EL SULTÁN: LOS SANJUANISTAS Y LA COMPRA- VENTA DE ESPECIAS}

Las necesidades financieras de mediados del siglo XV llevaron el Maestre a derogar la prohibición de practicar actividades comerciales. Para hacer frente al problema de la liquidez, entre 1440 y 1450, el Tesoro efectuó operaciones de compraventa de stock de especias, concluyendo negocios, desde un punto de vista práctico, directamente con el Sultán. En estos años los registros de cancillería atestiguan un importante número de ventas de especias efectuadas por la Orden a beneficio de mercaderes latinos -en su mayoría catalanes- que pagaban por adelantado con el compromiso de que la mercancía les fuera entregada a un año vista ${ }^{37}$. Se añadía una cláusula por la cual, en caso de que

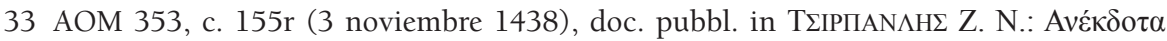

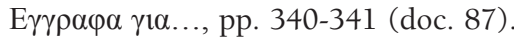

34 AOM 362, c. 209r (27 junio 1450).

35 AOM 362, c. 208r (12 abril 1450).

36 AOM 363, c. 256v (8 marzo 1452).

37 Sobre la importancia de Rodas en el comercio catalanoaragonés: CoulON D., Barcelone et le grand commerce d'Orient au Moyen Âge, Madrid-Barcelona, 2004 y DURAN I PUjOL M., FELIU I MONTFORT G., "El comerç català amb l'illa de Rodes als primers anys del segle XVI", en NARBONA VizCaíno R. (ed.), XVIII Congrés Internacional d'Història de la Corona d'Aragó (València, 2004), Actes, II, Valencia, 2005, pp. 1224-1228; DuRAN I DuElt D., "Presencia hispánica en Rodas. A propósito del Albergue de la Lengua de España", Memòries de la Reial Acadèmia Mallorquina d'Estudis Genealògics i Històrics, 19 (2009), pp. 97-112; ID., "El comercio entre España y Bizancio en los siglos XIII al XV", en Pérez Martín I., BÁdenas de la PeÑa P. (eds.), Bizancio y la Península Ibérica. De la Antigüedad Tardía a la Edad Moderna, Madrid, 2004, pp. 323-347; ID., Manual del viatge fet per Berenguer Benet a Romania, 1341-1342. Edició i comentari, Barcelona, 2002. Sobre la relación entre los mercaderes catalanoaragoneses y el Convento véase Soldani M. E., Duran i DuElt D., "Religion, Warfare and Business in Fifteenth Century Rhodes, en Religion and religious Institution in the European Economy. 
las especias no hubiesen sido entregadas según los acuerdos, se preveía la restitución de la cantidad de dinero adelantada más un interés de alrededor del $21 \%$, gestionando de esa forma la transacción con las modalidades de un préstamo $^{38}$. Al catalán Nicolau Correguer, que en 1.450 compró 35 quintales de pimienta al precio de 50 ducados por quintar, con un valor total de 1.750 ducados, el tesorero le prometía la entrega de la mercancía en el término de un año. En caso de que no se hubiese podido realizar dicha entrega, al mercader se le habría devuelto una cantidad de dinero de 60 ducados y medio de Rodas por quintar ${ }^{39}$.

¿Eran estas ventas ficticias o reales? Y, en ese segundo caso, ¿cómo y dónde se proveían los Sanjuanistas de esas especias? De abastecer a la Orden de especias se encargaron los mercaderes que tenían acceso directo al mercado alejandrino y que podían, pues, llegar a salvo a Rodas bajo la protección de los salvoconductos concedidos por el Maestre. La isla tenía la función de plaza de redistribución de las especias, constituyendo para este tipo de tráfico un espacio propicio si se considera que allí los mercaderes podían sustraerse al pago de los altos impuestos venecianos ${ }^{40}$. Las transacciones de compra se realizaban con el Sultán mameluco a través de la mediación de un singular personaje, el musulmán valenciano Galip Ripoll, mercante del grande Soldano de Babillonia ${ }^{41}$. El primero de noviembre de 1448 el tesorero afirmaba haber recibido de Ripoll, por mano de su factor Habryaym Valentero, 100 quintales de pimienta por un precio de 9.000 ducados de Rodas. El Tesoro le habría pagado esta cantidad de dinero a 15 meses vista y, en caso de dilación, se le

1000-1800", Acts of the XLIII Study Week, AmmannATI F. (ed.), Fondazione Istituto Internazionale di Storia Economica "F. Datini", Florencia, 2012, en part. el parráfo 2. The Catalan-Aragonese in Rhodes: the power of the group.

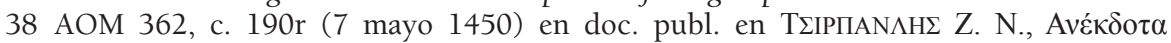

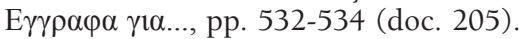

39 AOM 363, c. 375r (20 marzo 1450).

40 Apellániz Ruiz de GalarReta F., "Lower-Rank Actors in Elite Networks: Venetian Merchants in Alexandria (early 15th century)", comunicación presentada en el The fifty-sixth annual meeting of Renaissance society of America, Venecia (8-10 abril 2010) en la sessión In Search of the Venetian Popolani II: Social and Economic Practices, en curso de publicación.

41 Sobre este personaje emblemático: Servodio Peccator notaio in Venezia e Alessandria

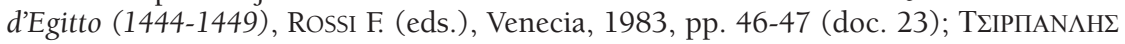

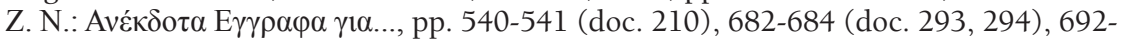
694 (doc. 301), 723-726 (doc. 314, 315), 758-760 (doc. 333); SARNOWSKY J., Macht und Herrschaft..., pp. 374-375; APELlÁNiz RuIZ DE GALARRETA F. J., "Vasallo del rey, mercader del sultán. La carrera de Galip Ripoll / Ghalib inb Rufa'il", en DURAN DUELT D. (coord.), Un Mar de Leyes. De Jaime I a Lepanto, Barcelona, 2008, pp. 147-154 y ID., Pouvoir et finance en Méditerranée pré-moderne: le deuxième état Mamelouk et le commerce des épices (1382-1517), Barcelona, 2009, pp. 127-129. 
habría atribuido un interés. Es particularmente interesante la clausula insertada al final del documento donde se declaraba que, en caso de que la Orden entrara en guerra con cum aliquibus infidelibus aut nationibus christianorum, a Ripoll y a sus factores se les habría garantizado la libre entrada y estancia en Rodas para recibir el dinero que se les debía sin que pudiese ser secuestrado por ningún cristiano ni infiel ${ }^{42}$. A Ripoll, definido como mercader musulmán valenciano en ese momento establecido en la ciudad de Alejandría, en mayo de 1450 le fue otorgado un salvoconducto por cuya redacción se denota la continuidad de este comercio entre Alejandría y Rodas. A él y a sus factores se permitía, en efecto, descargar, cargar, estar, partir y volver a Rodas a su voluntad y, allí, contratar, vender y comprar según el uso de los mercaderes ${ }^{43}$.

En este ambiguo espacio de frontera donde se combatía con el enemigo y al mismo tiempo se hacían negocios con él -negocios que permitían al sultán mantener sus propios ejércitos-, las relaciones entre los Sanjuanistas y sus vecinos musulmanes no se redujeron al marco del conflicto. ${ }^{44}$ Por lo menos a partir de los capítulos de paz concluidos entre el Sultán y la Orden en 1403, en Alejandría los rodiotas tenían su propio consulado ${ }^{45}$. El oficio vitalicio concedido al rodiota Antonio Cornetti en 1438 debió finalizar con el ataque de 1440 y el de 1444, pero gracias a una delegación enviada a negociar el año siguiente se restablecieron los tratados y, probablemente, se restituyó la figura del cónsul. En el otoño de 1445, una galera capitaneada por Jacques Coeur, platero del rey de Francia Carlos VII, transportó a Alejandría al florentino Bernardo Salviati, embajador del Hospital. Le embajada debió tener éxito ya que en los años siguientes encontramos otra vez el nombramiento de cónsules de Rodas en Alejandría. En el otoño de 1451 el ciudadano rodiota Michali Malii recibió ese cargo para los siguientes tres años, con todos los honores y beneficios atribuidos a sus predecesores. A Marco Sostem, que en aquel momento ocupaba el mismo cargo en Alejandría, se le pedía que lo acogiera y lo pusiera en posesión del funducq ${ }^{46}$.

Las relaciones con el Sultán concernían asimismo al rescate de prisioneros y, en este caso también, las tratativas era llevadas a cabo mediante la intervención de mercaderes musulmanes. En el marzo de 1453 otra vez Galip

42 AOM 361, cc. 276v-277r (1 noviembre 1448).

43 AOM 362, cc. 208r-v (27 mayo 1450).

44 Apellániz Ruiz de Galarreta F. J., Pouvoir et finance...

45 Giacomo Bosio, Dell'istoria della sacra religione et illustrissima militia di S. Giovanni Gierosolimitano di Giacomo Bosio, 2 voll., Roma, 1594, vol. II, pp. 116-117.

46 AOM 363, c. 242r (11 septiembre 1451). Para el cargo vitalicio de Antonio Cornetti,

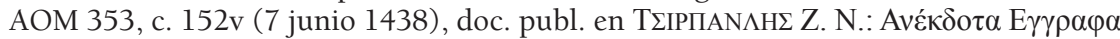
$\gamma 1 \alpha \ldots$, pp. 326-327 (doc. 76). 
Ripoll, mercader del Sultán, definido por el Maestre como amico nostro, fue encargado del rescate de unos prisioneros cristianos presos por los musulmanes en Trípoli: se trataba de Fernando de Ribadenera, Andrea de Portilio, Bernardo Uber, Joan de Entrages y Joan de Sagonino. Para su liberación el mercader del Sultán debería anticipar 1.000 ducados de Venecia o bien 1.000 doblas moriscas de oro, es decir, 200 ducados o doblas por cada uno, que se le habrían devuelto en Rodas. En una carta sucesiva de octubre del mismo año dirigida a Ripoll, pero destinada al Sultán, los Sanjuanistas aceptaban la propuesta del Sultán de pagar 200 ducados de más y determinaban la modalidad de entrega de los presos. ${ }^{47}$

\section{CONCLUSIONES}

Con este ensayo he querido destacar cómo en Rodas, una isla puesta en un área de frontera caracterizada por un alto nivel de belicosidad y situada en la intersección entre las principales rutas de comercio levantinas, la economía de guerra se integraba en el comercio cross-cultural. Esta situación fue el resultado de la convergencia de distintos factores que crearon a la vez una serie de necesidades determinantes para la supervivencia de la isla: la peculiaridad de su gobierno, puesto en las manos de una orden monástico-militar cuya principal tarea era la defensa de la Cristiandad; la población sujeta, una población multicultural; la precariedad de su naturaleza insular, debida a su endémico problema de despoblamiento, a su incapacidad para ser autosuficiente en tema de aprovisionamientos, al encontrarse constreñida por los dominios musulmanes, a la lejanía de los principales recursos económicos procedentes de las posesiones europeas. Estos factores hicieron necesario, por parte de las instituciones, de favorecer la inserción de la isla en las redes mercantiles del comercio regional e internacional que funcionaban en base a lazos culturales, étnicos y religiosos, y de valerse de la colaboración de agentes mediadores cross-cultural, capaces de atravesar estos confines, que podían ser empleados en la negociación con los territorios vecinos tanto a nivel comercial, como en cuestiones diplomáticas y en el rescate de cautivos.

47 AOM 363, c. 287 r (6 marzo 1453) y AOM 363, cc. 287 r-v (29 octubre 1453). 